\title{
The oxidation performance of plasma-sprayed NiAl bond coat: Effect of Hf addition in bond coat and substrate
}

DOI:

10.1016/j.surfcoat.2018.08.005

\section{Document Version}

Accepted author manuscript

Link to publication record in Manchester Research Explorer

\section{Citation for published version (APA):}

Zhao, C., Luo, L., Xiao, C., Zhao, X., Wang, X., Guo, F., \& Xiao, P. (2018). The oxidation performance of plasmasprayed NiAl bond coat: Effect of $\mathrm{Hf}$ addition in bond coat and substrate. Surface and Coatings Technology, 352, 49-58. https://doi.org/10.1016/j.surfcoat.2018.08.005

\section{Published in:}

Surface and Coatings Technology

\section{Citing this paper}

Please note that where the full-text provided on Manchester Research Explorer is the Author Accepted Manuscript or Proof version this may differ from the final Published version. If citing, it is advised that you check and use the publisher's definitive version.

\section{General rights}

Copyright and moral rights for the publications made accessible in the Research Explorer are retained by the authors and/or other copyright owners and it is a condition of accessing publications that users recognise and abide by the legal requirements associated with these rights.

\section{Takedown policy}

If you believe that this document breaches copyright please refer to the University of Manchester's Takedown Procedures [http://man.ac.uk/04Y6Bo] or contact uml.scholarlycommunications@manchester.ac.uk providing relevant details, so we can investigate your claim.

\section{OPEN ACCESS}




\title{
The oxidation performance of plasma-sprayed NiAl bond coat: effect of Hf addition in bond coat and substrate
}

\author{
Chunshan Zhao
}

School of Materials Science and Engineering, Shanghai Jiao Tong University, Shanghai 200240, China

Lirong Luo

School of Materials Science and Engineering, Shanghai Jiao Tong University, Shanghai

$$
\begin{aligned}
& \text { 200240, China } \\
& \text { Chengbo Xiao }
\end{aligned}
$$

Science and Technology on Advanced High Temperature Structural Materials laboratory, Beijing Institute of Aeronautical Materials, Beijing 100095, China

Xiaofeng Zhao

School of Materials Science and Engineering, Shanghai Jiao Tong University, Shanghai 200240, China

$$
\text { Xin Wang }
$$

Konca Solar Cells Co., Ltd, Wuxi 214000, China

Fangwei Guo

School of Materials Science and Engineering, Shanghai Jiao Tong University, Shanghai 200240, China

Ping Xiao

School of Materials, University of Manchester, MSS Tower, Manchester M13 9PL, United Kingdom

School of Materials Science and Engineering, Shanghai Jiao Tong University, Shanghai 200240, China

*Corresponding author: Xiaofeng Zhao

Email: xiaofengzhao@sjtu.edu.cn; Tel: +86-21-54742561; Fax: +86-21-54742561 


\section{Abstract}

$\mathrm{NiAl}$ bond coats with and without $\mathrm{Hf}$ addition (0.1 at\%) were deposited on two types of superalloy substrates (i.e., DZ125L, no Hf, and DZ125, 0.51 at\% Hf) using plasma spraying technique, and isothermally oxidized at $1150{ }^{\circ} \mathrm{C}$. It demonstrates that $\mathrm{Hf}$ addition in the bond coat is more effective than in the superalloy substrate for improving the bond coat oxidation resistance. In addition, though the substrate chemistry could affect the bond coat oxidation performance, this effect was very sensitive to the chemistry of the bond coat - obvious for the RE (reactive element)-free NiAl bond coat, but less obvious for the RE-containing bond coats (NiAlHf and NiCoCrAlY). Moreover, compared with the NiCoCrAlY bond coat, the NiAlHf bond coat showed significantly improved oxidation resistance, regardless of the substrate chemistry, suggesting that NiAlHf bond coat prepared by plasma spraying is a promising candidate for the thermal barrier coating application.

Keywords: Metal coatings; High temperature oxidation; Superalloy; Oxide adherence; Plasma spraying

\section{Introduction}

$\beta-\mathrm{NiAl}$ is considered as one of the most promising materials to replace conventional MCrAlY (M=Ni, Co or both) for high temperature protection of superalloys and bond coats in thermal barrier coating (TBC) systems because of its high strength, high melting point, low density, good isothermal oxidation resistance and low cost $[1,2]$. In view of this, NiAl coatings fabricated by various methods, such as electron beam physical vapor deposition (EB-PVD) [3, 4], pack cementation [5-7] and chemical vapor deposition (CVD) $[8,9]$, have been developed and investigated. In general, these coatings possess good oxidation performance while still encounter some problems. For example, the EB-PVD process is high cost and hard to control the composition, and the other methods will usually incorporate a certain amount of elements from superalloy substrate during fabrication (typically at $>1100{ }^{\circ} \mathrm{C}$ ), which not only deteriorate the chemical stability, but also strongly influence the oxidation 
performance of these coatings.

As NiAl is a very stable compound, thermal spraying methods are also considered for its deposition. To avoid excessive oxidation of NiAl powder particles during spraying, low temperature spraying methods like high velocity oxygen fuel (HVOF) and even cold spraying are being employed. For example, Hearley etc. [10] investigated the spraying parameters of HVOF on the quality (e.g., oxygen content, porosity) of $\mathrm{NiAl}$ coatings. Zhang etc. [11] used cold spraying followed by a annealing process to fabricate NiAl coating. As a versatile and economic method, air plasma spraying (APS) has been widely applied to deposit bond coats (e.g., MCrAlY) in the hot sections of industrial gas turbines [12-14]. However, compared with MCrAlY, deposition of NiAl by APS is more challenging and used less often [15-17]. Firstly, the high content of oxide inclusions formed during high temperature spraying deteriorates the oxidation performance of NiAl. Secondly, the brittleness of NiAl at ambient temperature may affect the adherence with superalloy substrate. The thermally sprayed NiAl material is typically $95 / 5$ or $90 / 10$ wt.\% composition alloys. However, as will be shown in this work, with optimized processes and parameters, the APS NiAl bond coats reveal good oxidation performance during high temperature exposure.

Previous research show that though NiAl possesses good isothermal oxidation resistance, the thermally grown oxide (TGO) formed on it spalls readily during thermal cycling due to poor adherence, which hinders its application. To improve the TGO adherence, a third additional element is essential, particularly reactive elements (REs), such as Hf, Zr, Y, which have been reported extensively [18-20]. To take full advantage of the beneficial effect, RE is usually directly added to alloys or bond coats in forms of alloying element or oxide dispersion. In this case, RE is prone to be incorporated to growing the TGO once oxidation occurs, which not only modifies the microstructure and morphology of the TGO, but also influences its growth rate and adherence. Previous reports also showed that the oxidation performance of coatings is strongly dependent on the chemical composition of the superalloy substrate, especially when containing REs, such as $\mathrm{Hf}, \mathrm{Zr}$, Ti [5, 21, 22]. It is suggested that 
though various substrate elements diffuse into coatings and influence its oxidation performance, the most significant effect should be ascribed to REs. However, comparisons of the effect of RE addition in the bond coat and the superalloy are rarely reported because investigations published so far have tended to consider just a single bond coat or substrate composition. Moreover, it is difficult to isolate the effect of REs from other alloying elements both in the bond coat and superalloy. Therefore, characterization of the effect of RE both in the bond coat and the superalloy substrate on the bond coat oxidation performance is very meaningful.

This work attempts to develop an economic and high oxidation performance bond coat applied in the industrial gas turbines, together with characterization of RE effect both in the bond coat and superalloy substrate. In this work, Hf is chosen as the model element, which is the most widely used additive element both in superalloy and bond coat $[5,18,23]$. Four bond coat systems were used: undoped NiAl and Hf-doped NiAl bond coats both deposited on one Hf-free superalloy (DZ125L) and one Hf-containing superalloy (DZ125), respectively. DZ125L alloy is a directionally solidified nickel-based superalloy, and its improved version DZ125, is widely used for gas turbines and boilers due to its good thermo-mechanical properties [24, 25]. In addition, a conventional NiCoCrAlY bond coat was also deposited on these two superalloys for comparison. The oxidation behavior of the bond coats, including the oxidation rate, TGO microstructure and phases, TGO spallation were examined, and the influencing factors were also analyzed and discussed.

\section{Experiment}

\subsection{Materials and sample preparation}

The nominal compositions of the bond coats and the superalloy substrates are given in Table 1. The composition of $\mathrm{NiAl}$ is stoichiometric (50:50 in atomic ratio), and the NiAlHf is Ni-49.9Al-0.1Hf (in at.\%). Both materials were obtained by arc-melting, and then annealed at $1200{ }^{\circ} \mathrm{C}$ for $100 \mathrm{~h}$ in argon flow to homogenize the composition. The feedstock powders for APS were obtained by crushing and milling the bulk obtained from arc-melting in a planetary ball mill, and then sieved to the range 
of 40-110 $\mu \mathrm{m}$. The NiCoCrAlY powder is commercial (Amdry 365-2, Sulzer Metco).

The superalloy substrates $\left(60 \times 40 \times 4 \mathrm{~mm}^{3}\right)$ were grit blasted $\left(\mathrm{Al}_{2} \mathrm{O}_{3}, 30 \mathrm{mesh}\right)$, and then a bond coat was deposited on them. In this work, a supersonic atmospheric plasma spray (SAPS) system (Model: HEPJ- II ; National Key Laboratory For Remanufacturing, Beijing, China) was used for coating deposition. The feedstock powder was radially injected into the plasma jet by an internal injection port with an inlet diameter of $2 \mathrm{~mm}$ inside a laval nozzle [26, 27]. The samples were fabricated with identical parameters shown in Table. 2. To densify the bond coats and get chemical bonding to the substrates, a vacuum $\left(10^{-4}-10^{-3} \mathrm{~Pa}\right)$ annealing at $1100{ }^{\circ} \mathrm{C}$ for $4 \mathrm{~h}$ was employed. Afterwards, the samples were cut into $10 \times 10 \mathrm{~mm}^{2}$ plates. In order to remove the surface undulations, the bond coats were mechanically ground down to the same thickness $(\sim 150 \mu \mathrm{m})$ with final polishing of $0.05 \mu \mathrm{m}$ using standard metallographic approaches, and then were ultrasonically cleaned in acetone.

To examine the oxidation performance of the bond coats, isothermal oxidation test was conducted at $1150{ }^{\circ} \mathrm{C}$ in a chamber furnace at atmosphere environment. The samples were taken out of the furnace after a required exposure time ranging from 10 to $200 \mathrm{~h}$. The test temperature employed in this study is severe for bond coat oxidation, especially for the NiCoCrAlY (usually $<1100{ }^{\circ} \mathrm{C}$ ). The choice of the test temperature is to examine the oxidation performance of these bond coats at higher temperature, and to seek a potential material for bond coat which could be applied in higher temperature environment.

Table 1 Chemical compositions of the bond coats and superalloy substrates (at.\%)

\begin{tabular}{ccccccccccc}
\hline Material & Cr & Co & W & Mo & Al & Ti & Ta & Hf & Y & Ni \\
\hline NiAl & $/$ & $/$ & $/$ & $/$ & 50 & $/$ & $/$ & $/$ & $/$ & 50 \\
\hline NiAlHf & $/$ & $/$ & $/$ & $/$ & 49.9 & $/$ & $/$ & 0.1 & $/$ & 50 \\
\hline NiCoCrAlY & 16.5 & 22.4 & $/$ & $/$ & 19.7 & $/$ & $/$ & $/$ & 0.3 & Bal. \\
\hline DZ125L & 10.2 & 9.96 & 2.24 & 1.22 & 10.9 & 4.29 & 1.30 & $/$ & $/$ & Bal. \\
\hline DZ125 & 9.9 & 9.89 & 2.29 & 1.31 & 11.6 & 1.17 & 1.21 & 0.51 & $/$ & Bal. \\
\hline
\end{tabular}




\subsection{Characterization}

The morphology and microstructure of the samples were observed using an optical microscope (BX51M, Olympus) and a scanning electron microscope (SEM, Inspect F50, FEI).

The TGO spallation degree (the ratio of the spalled area to the total area of the TGO) was evaluated. After cooling to room temperature, almost the entire area of the TGO surface $\left(10 \times 10 \mathrm{~mm}^{2}\right)$ was taken by the optical microscope with a $5 \times$ objective lens. Therefore, for each sample, more than 6 images were taken with an individual area of $2.6 \times 3.4 \mathrm{~mm}^{2}$. The spallation degree was evaluated from these images based on the contrast of the TGO and the exposed bond coat surface, using the image processing software (ImageJ, NIH) [28, 29].

The phase compositions and element distributions of the samples were analyzed by an X-ray diffraction (Ultima IV, Rigaku) and an energy-dispersive spectroscopy (EDS, Rontec), respectively.

Table 2 Air plasma spray parameters for the bond coat deposition

\begin{tabular}{cc}
\hline Spray parameters & Bond coat \\
\hline Spray distance (mm) & 100 \\
Arc current (A) & 400 \\
Voltage (V) & 148 \\
Ar flow rate (SLPM) & 91.5 \\
H$_{2}$ flow rate (SLPM) & 15.9 \\
Carrier gas flow rate (SLPM) & 5 \\
Gun speed (mm/s) & 800 \\
\hline
\end{tabular}

SLPM=Standard litres per minute

\section{Result}

\subsection{Bond coat microstructure}

Fig. 1 shows the microstructures of the samples after vacuum annealing. All the 
bond coats showed a splat microstructure characterized by the presence of oxide stringers and voids at the splat boundaries as typical APS coatings [30]. Fig. 2 presents the bond coat microstructure evolution before and after vacuum annealing. It is visible that $\beta-\mathrm{NiAl}$ phase in the $\mathrm{NiAl}(\mathrm{Hf})$ bond coats experienced phase segregation during spraying, in which Ni-rich phases (bright contrast, 73-85 wt.\% Ni) primarily located along splat boundaries. This phenomenon has also been observed by previous experiments, while the mechanism is not fully understood yet $[10,15,31]$. After annealing, the $\mathrm{NiAl}(\mathrm{Hf})$ bond coats were more homogeneous and without phase separation. This is consistent with the XRD (Fig. 3) and EDS analysis which confirmed that all the $\mathrm{NiAl}(\mathrm{Hf})$ bond coats consisted of a single $\beta$-NiAl phase with the composition ( 48.2:51.8 at.\% Al:Ni) slightly deviated from the stoichiometry. Hf-rich precipitates were observed both on the as-sprayed and as-annealed NiAlHf bond coats. However, the segregation of Hf was less obvious after annealing, suggesting that most of the $\mathrm{Hf}$ was dissolved in NiAl during annealing. The bond coat/superalloy interface was adherent and contiguous with the presence of some randomly distributed defects $\left(\mathrm{Al}_{2} \mathrm{O}_{3}\right.$ grit or pores $)$ in the as-sprayed state. After vacuum annealing, an interdiffusion zone formed between the bond coat and the superalloy substrate. In addition, some newly formed defects (e.g., oxides or pores) were observed after vacuum annealing (Fig. 2f). For the NiCoCrAlY bond coats, most of the $\beta$ phase was dissolved in the $\gamma / \gamma^{\prime}$ phase during spraying, which precipitated out after vacuum annealing. 

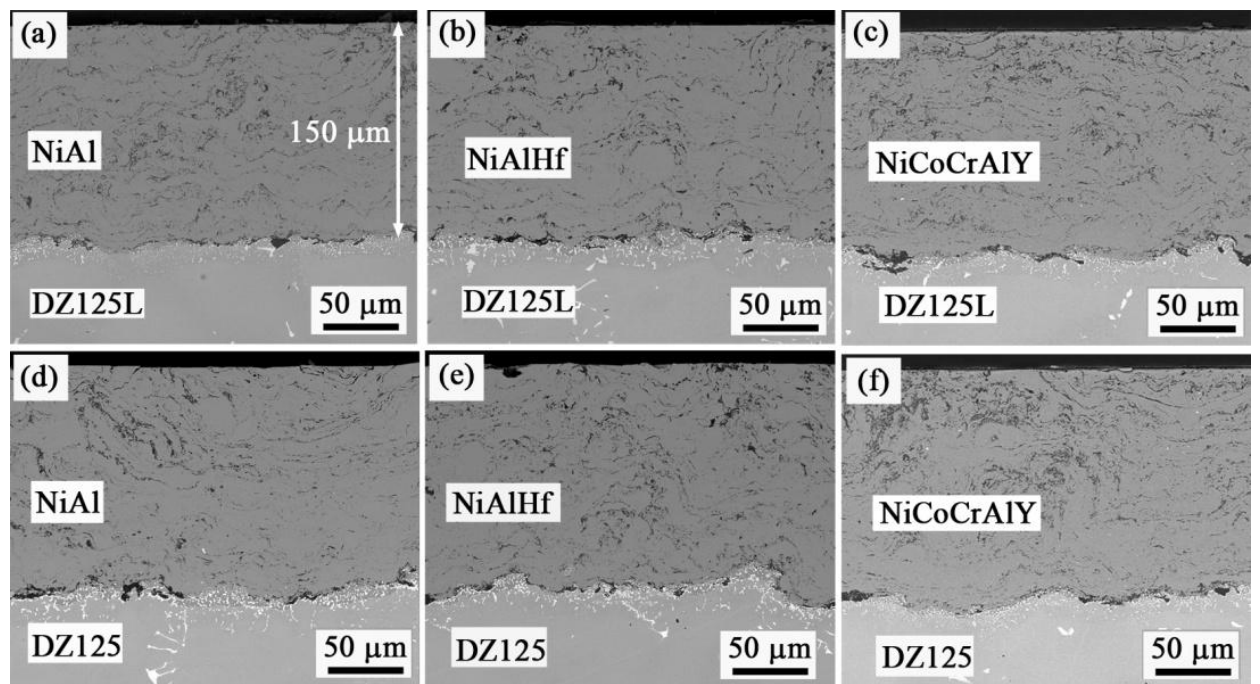

Fig. 1 The microstructures of the as-received samples after vacuum annealing: (a-c) NiAl, NiAlHf and NiCoCrAlY bond coats deposited on DZ125L, respectively; (d-f) NiAl, NiAlHf and NiCoCrAlY bond coats deposited on DZ125, respectively.
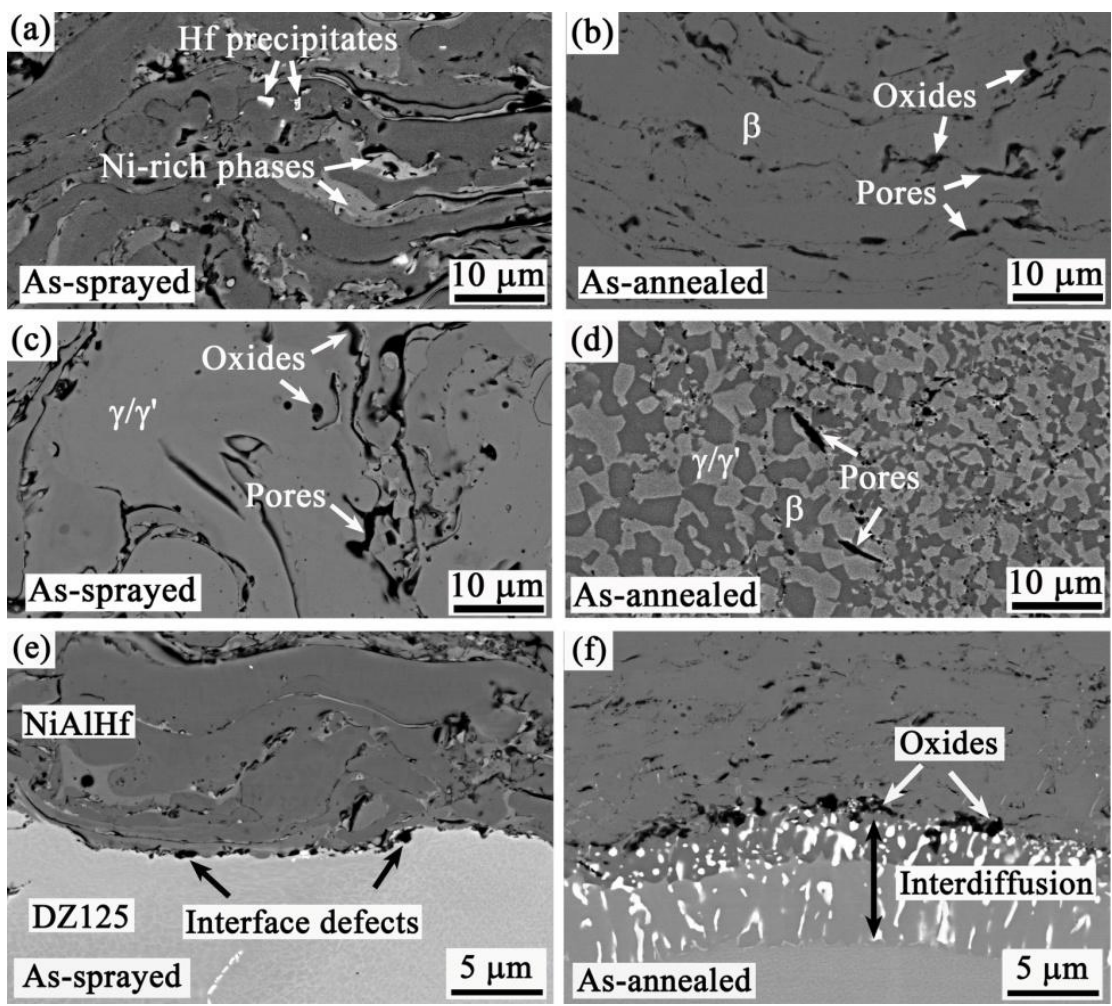

Fig. 2 Cross-sectional micrographs of: (a) as-sprayed NiAlHf bond coat, (b) as-annealed NiAlHf bond coat, (c) as-sprayed NiCoCrAlY bond coat, (d) as-annealed NiCoCrAlY bond coat, (e) the bond coat/substrate interface of NiAlHf+DZ125 in the as-sprayed sate and (f) the bond coat/substrate interface of NiAlHf+DZ125 after vacuum annealing. 


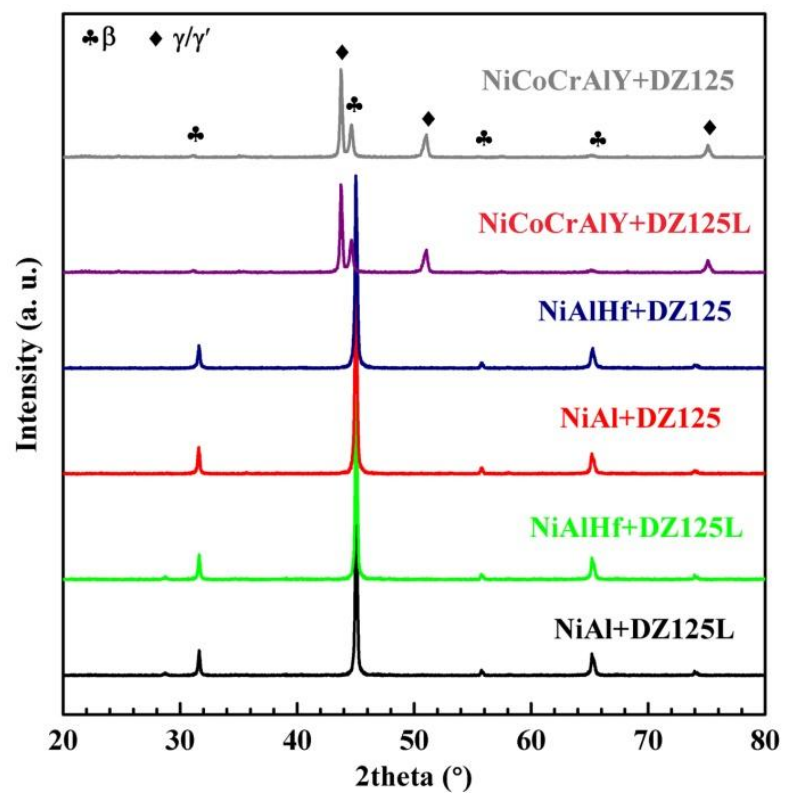

Fig. 3 The XRD patterns of the bond coats after vacuum annealing.

\subsection{TGO spallation behavior}

Fig. 4 shows the optical plan-view micrographs of the bond coats after oxidation for different times at $1150{ }^{\circ} \mathrm{C}$. The TGO formed on the $\mathrm{NiAl}(\mathrm{Hf})$ bond coats primarily consisted of $\mathrm{Al}_{2} \mathrm{O}_{3}$ with some randomly distributed Ni-rich oxides nodules (primarily $\mathrm{NiAl}_{2} \mathrm{O}_{4}$ spinel, confirmed by EDS and XRD analysis in Fig. 6). However, for the NiCoCrAlY bond coats, a large amount of spinel oxide formed only after $10 \mathrm{~h}$ oxidation. For the NiCoCrAlY material with defect-free microstructure (e.g., alloy), the overall $\mathrm{Al}$ concentration ( $\sim 20$ at. $\%$ ) is sufficient to form a protective $\mathrm{Al}_{2} \mathrm{O}_{3}$ oxide layer, at least during short time oxidation [32]. However, for the plasma-sprayed bond coats with a lot of defects (e.g., cracks, pores) and oxide stringers at splat boundaries, spinel phase could form due to local Al depletion. For example, if a splat at the bond coat surface is isolated by defects and/or oxide stringers, spinel oxide would form locally as the Al supply from neighboring materials is inhibited. Compared with the $\mathrm{NiAl}(\mathrm{Hf})$ bond coat, the NiCoCrAlY bond coat had a lower overall Al concentration, which means lower local Al supply, leading to a larger amount of spinel oxide formed during oxidation. In addition, as the growth rate of spinel is higher than $\mathrm{Al}_{2} \mathrm{O}_{3}$ [33], the fast growth of spinel accelerated the Al depletion, which in turn promoted its formation. During cooling to room temperature, the TGO tended to spall, primarily 
around the spinel oxide, as shown in Fig. 4 and Fig. 5. It is visible that delamination firstly occurred at the porous regions around the spinel, then the entire spinel oxide tended to delaminate, resulting in an inverted roof-shaped spall (Fig. 5d).

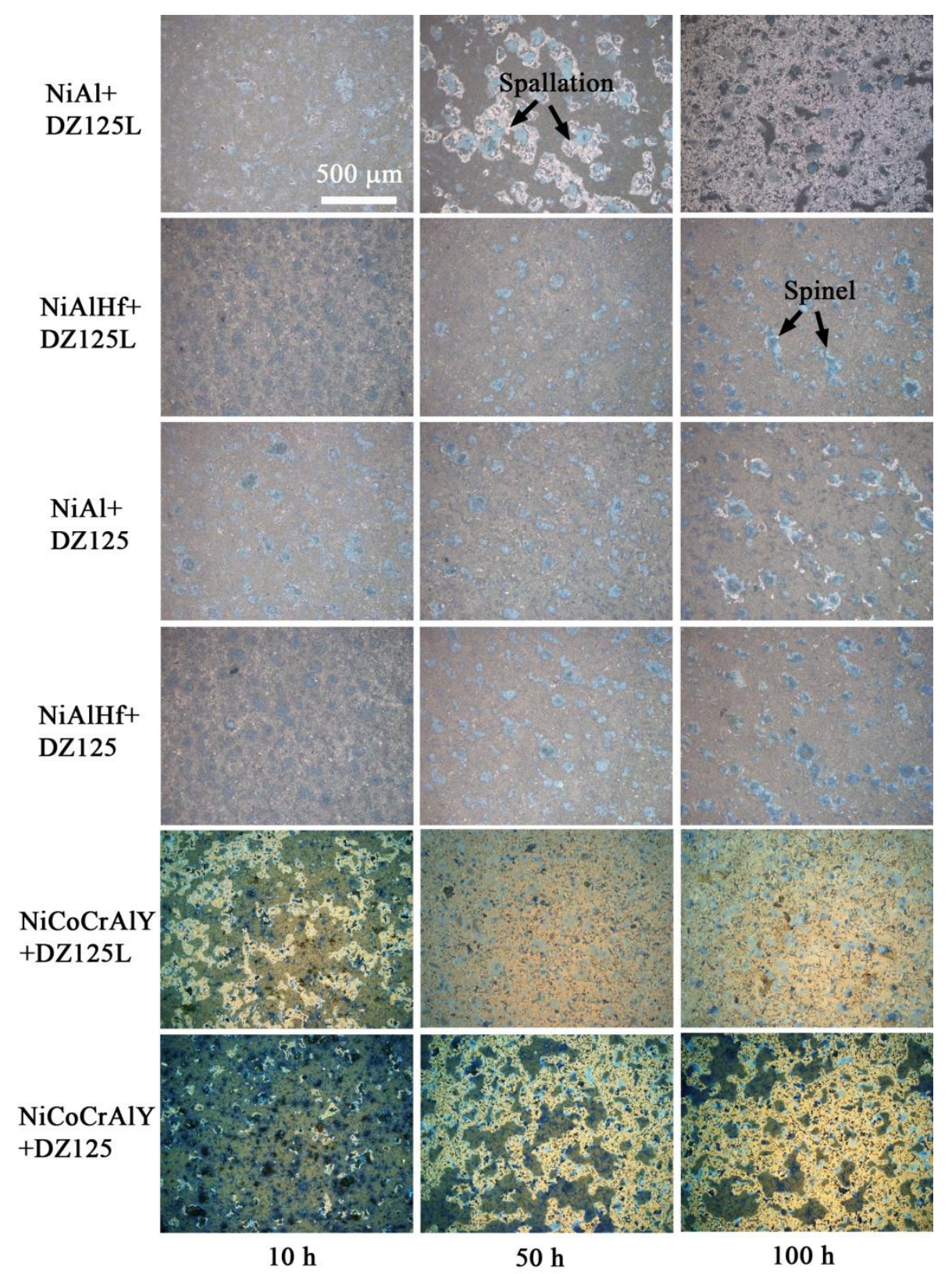

Fig. 4 The optical micrographs of the bond coats after oxidation at $1150{ }^{\circ} \mathrm{C}$ for 10,50 and $100 \mathrm{~h}$. The exposed metal surface (spallation area) appears bright and the spinel oxides appear blue marked by arrows.

The TGO spallation degree of the bond coats as a function of oxidation time is plotted in Fig. 7. For comparison, the experimental result by previous study of a APS NiCoCrAlY bond coat deposited on a Hastelloy X superalloy under the same oxidation conditions is also given [32]. After cooling to room temperature, these 
samples exhibited significantly different TGO spallation degree. The NiCoCrAlY bond coats suffered severe TGO spallation, regardless of the underlying substrates. For example, only after $50 \mathrm{~h}$ oxidation, the NiCoCrAlY bond coats on the two Hf-free superalloys (DZ125L and Hastelloy X) showed a $~ 80 \%$ TGO spallation degree, and that on the Hf-containing DZ125 was slightly better ( 58 \%). Compared with the NiCoCrAlY bond coats, the $\mathrm{NiAl}(\mathrm{Hf})$ ones showed much higher spallation resistance, except for the NiAl+DZ125L sample ( 73\%, 100 h). After 200 h oxidation, only $4.0 \%, 6.0 \%$ and $2.4 \%$ area spalled on the NiAlHf+DZ125L, NiAl+DZ125, and NiAlHf+DZ125, respectively.
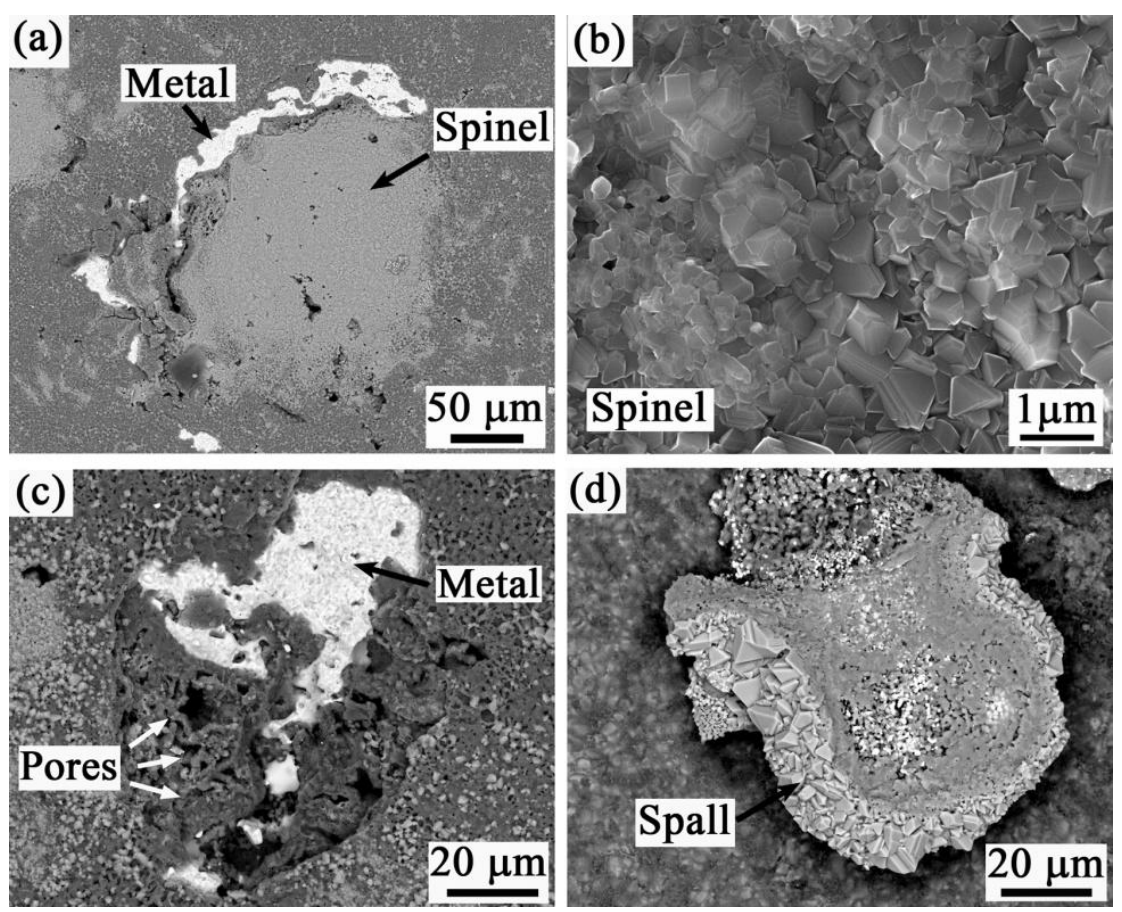

Fig. 5 A representative spallation behavior of the TGO on the NiAl+DZ125 sample after $100 \mathrm{~h}$ oxidation: (a) a spinel oxide with spallation around, (b) high- magnification image showing the spinel morphology, (c) the porous morphology around the spinel where spallation occurred and (d) an inverted roof-shaped oxide spall. 


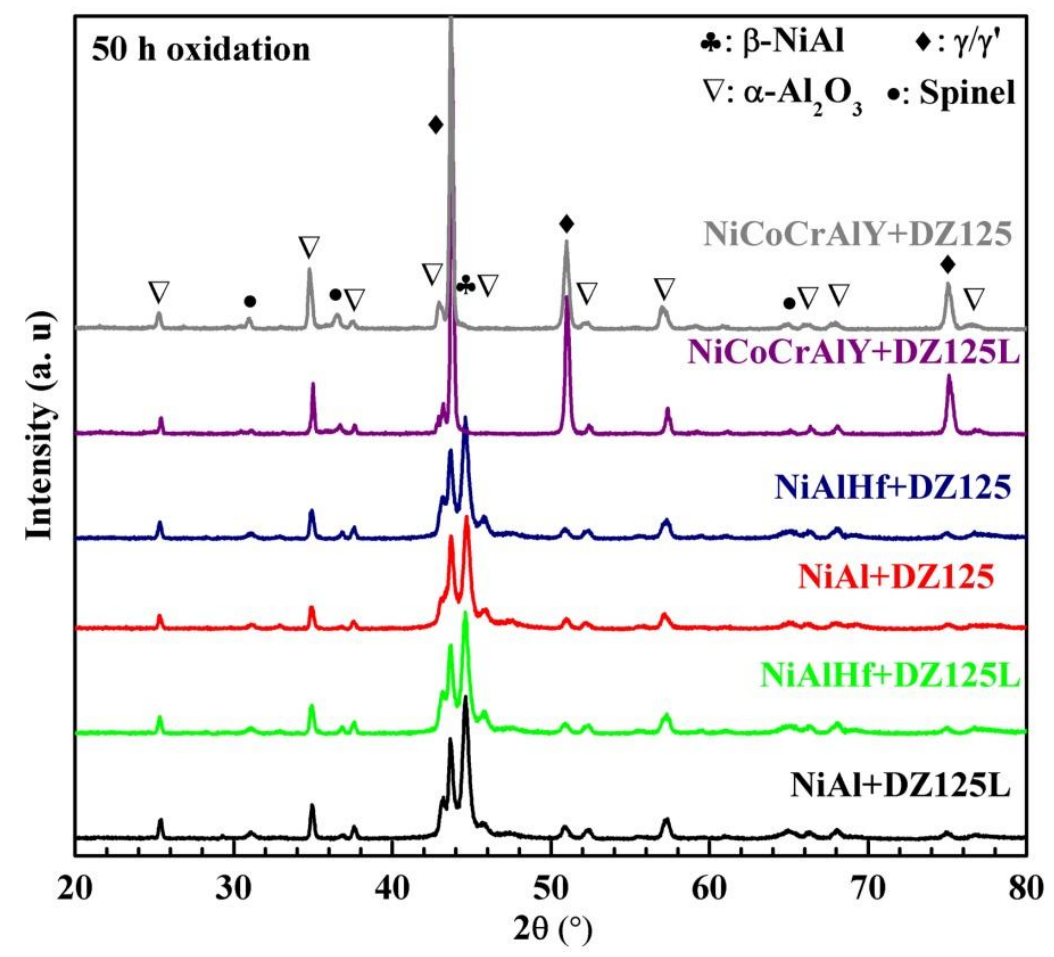

Fig. 6 The XRD patterns of the TGO on the samples after $50 \mathrm{~h}$ oxidation at $1150{ }^{\circ} \mathrm{C}$.

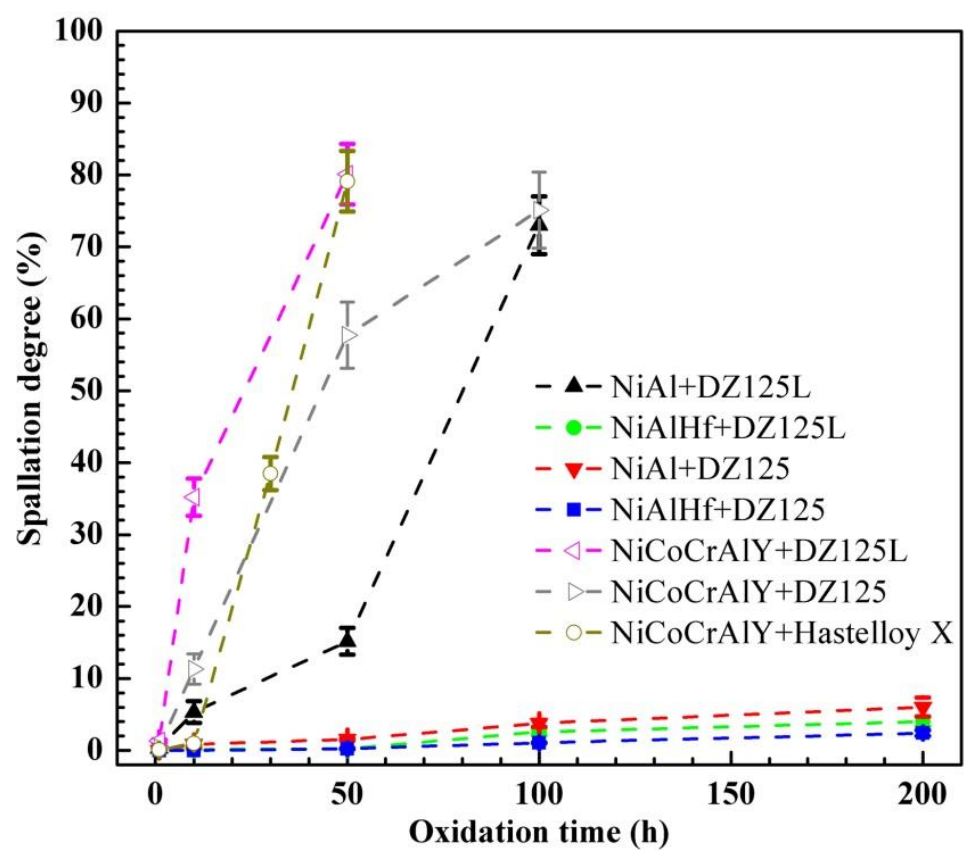

Fig. 7. TGO spallation degree as a function of oxidation time at $1150{ }^{\circ} \mathrm{C}$. The experimental result by previous study of NiCoCrAlY bond coat on a Hastelloy X superalloy $(22 \mathrm{Cr} 18 \mathrm{Fe} 9 \mathrm{Mo} 1.5 \mathrm{~W}$, in wt.\%, balanced by $\mathrm{Ni}$ ) under the same oxidation conditions is also given [32].

The excellent TGO spallation resistance of the two NiAlHf bond coats indicates the beneficial RE effect of Hf. An interesting phenomenon is that the substrate 
composition had a significant effect on the spallation resistance of the overlay bond coats. Most previous work studying the substrate effect have been focused on the diffusion coatings, which inherit the substrate chemistry greatly during fabrication at high temperature [34]. Another finding is that the substrate effect was more pronounced for the $\mathrm{NiAl}$ bond coat than the other ones - the NiAl bond coats showed much more different TGO spallation degree than the NiAlHf and NiCoCrAlY bond coats when being deposited on different substrates.

\subsection{TGO growth kinetics}

Fig. 8 shows the thicknesses of the TGO including $\mathrm{Al}_{2} \mathrm{O}_{3}$ and spinel oxide on the samples as a function of oxidation time. The average TGO thicknesses were measured at 50 equidistance points along the TGO layer on SEM cross-sectional images. The TGO thickness on the NiAl+DZ125L sample increased quickly and reached $7.5 \mu \mathrm{m}$ after $50 \mathrm{~h}$ oxidation when the TGO spalled severely. Compared with the $\mathrm{NiAl+DZ125L}$ sample, the NiAl bond coat on DZ125 showed a relatively lower TGO growth rate $(5.4 \mu \mathrm{m}, 50 \mathrm{~h})$. In addition, the oxidation rates of the NiAlHf bond coats were much lower than that of the $\mathrm{NiAl}$ ones, indicating the suppressing effect of $\mathrm{Hf}$ on TGO growth. Moreover, the two NiCoCrAlY bond coats showed highest oxidation rates, which were comparable regardless of the different substrates.

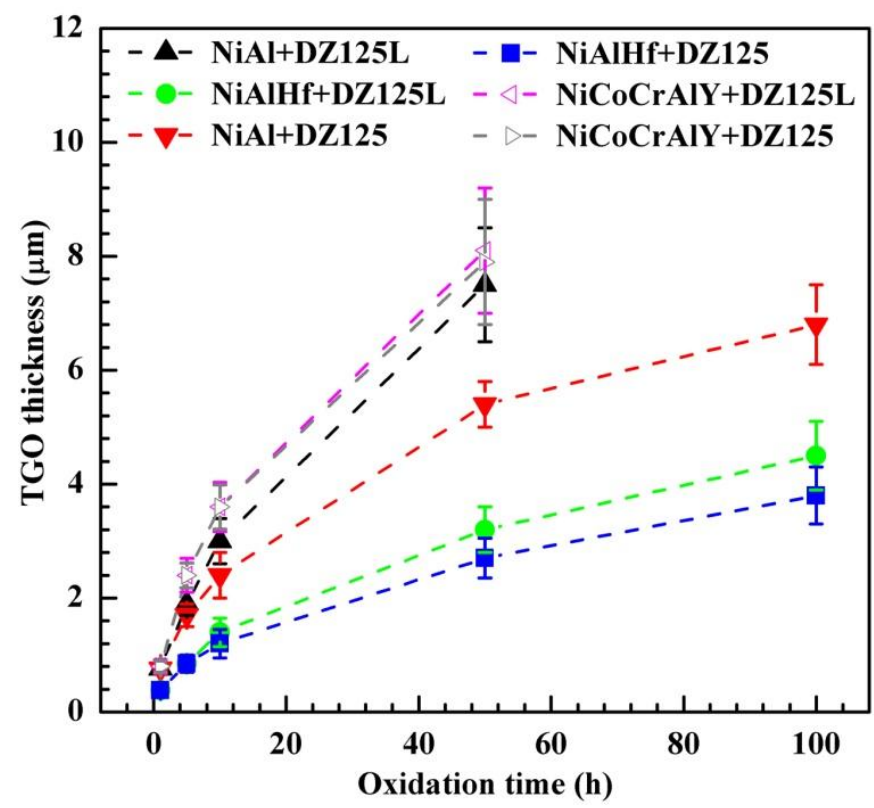

Fig. 8 The TGO thicknesses of the samples as a function of oxidation time at $1150{ }^{\circ} \mathrm{C}$. 


\subsection{TGO microstructure and morphology}

Fig. 9 presents the cross-sectional micrographs of the bond coats after $100 \mathrm{~h}$ oxidation at $1150{ }^{\circ} \mathrm{C}$ (the results of NiCoCrAlY bond coats were not given due to severe spallation). The TGO on NiAl+DZ125L showed a porous structure with equiaxed grains (Fig. 9 and Fig. S1) and spalled seriously. Though the TGO on $\mathrm{NiAl+DZ125}$ also showed an equiaxed structure, it was much denser with the absence of pores. However, for the two NiAlHf bond coats, a dense TGO layer with a columnar structure (Fig. S1) was formed. In addition, Hf-rich oxides $\left(\mathrm{HfO}_{2}\right)$ were observed within the TGO formed on them. This is consistent with the observations on the TGO surface morphologies in Fig. 10, which were taken at the regions far away from spinel oxide and hence represent the $\mathrm{Al}_{2} \mathrm{O}_{3}$ oxide. It shows that $\mathrm{NiAlHf}$ bond coats exhibited a more close-packed TGO morphology with the absence of $\mathrm{Al}_{2} \mathrm{O}_{3}$ whiskers which are indicative of the outward transport of $\mathrm{Al}$. Besides, $\mathrm{HfO}_{2}$ particles appeared at the grain boundaries at the TGO/gas interface. These phenomena indicate that $\mathrm{Hf}$ addition in the NiAl bond coats effectively changed the TGO growth mechanism, which has been reported widely by previous research [19, 23, 35].
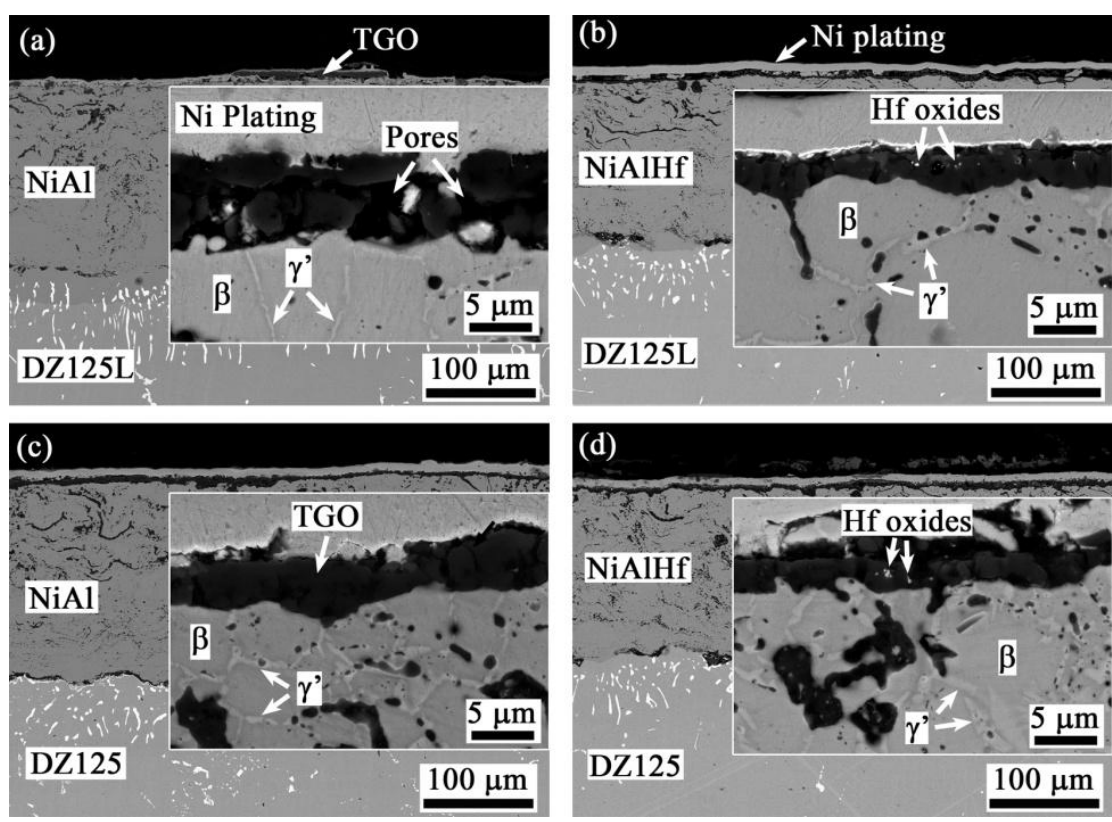

Fig. 9 The cross-sectional micrographs of the samples after $100 \mathrm{~h}$ oxidation at $1150{ }^{\circ} \mathrm{C}$ : (a) NiAl+DZ125L, (b) NiAlHf+DZ125L, (c) NiAl+DZ125 and (d) NiAlHf+DZ125. The insets present high-magnification images of the TGO microstructure. 

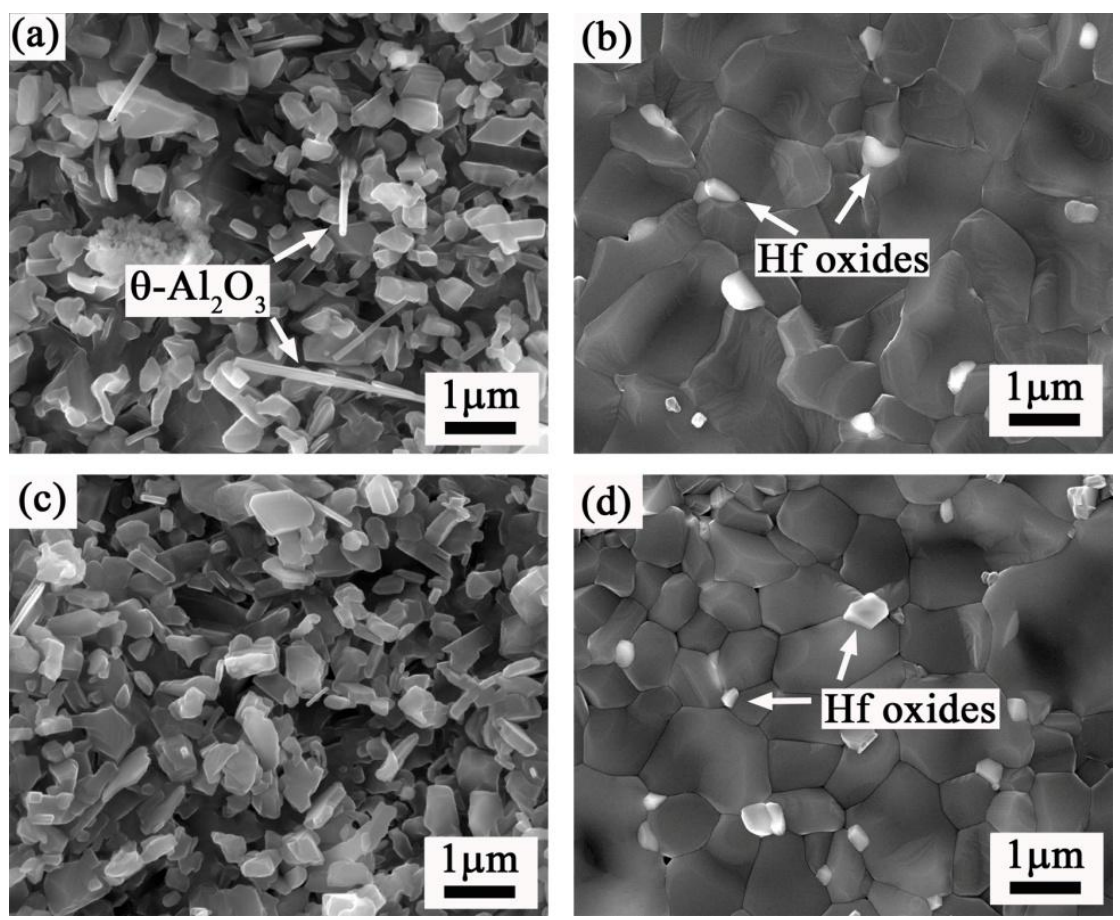

Fig. 10 The surface morphologies of the TGO formed on the bond coats after $100 \mathrm{~h}$ oxidation at $1150{ }^{\circ} \mathrm{C}$ : (a) NiAl+DZ125L, (b) NiAlHf+DZ125L, (c) NiAl+DZ125 and (d) NiAlHf+DZ125.

\subsection{Bond coat/superalloy substrate interdiffusion}

As described above, the substrate composition had a significant influence on the oxidation behavior of the bond coats, so it is of great necessity to characterize the chemical interdiffusion between the bond coats and the substrates. Fig. 11 presents the chemical depth profiles of the NiAl+DZ125 sample after $100 \mathrm{~h}$ oxidation. It shows that $\mathrm{Al}$ diffused from the bond coat into the substrate, which resulted in $\mathrm{Al}$ depletion. Meanwhile, a large amount of substrate elements, especially $\mathrm{Cr}(\sim 5$ wt. $\%)$ and $\mathrm{Co}(\sim 5$ wt.\%), diffused into the bond coat. In addition, Hf and Ti in DZ125 substrate were also found to diffuse into the bond coat, which segregated at the oxide stringers within the bond coat and residual $\mathrm{Al}_{2} \mathrm{O}_{3}$ grit at the bond coat/substrate interface, as shown in Fig. 12. This is due to their high affinity with oxygen ions, leading to be captured by $\mathrm{Al}_{2} \mathrm{O}_{3}$ oxide at these two areas. For example, $\mathrm{Hf}$ could react with $\mathrm{Al}_{2} \mathrm{O}_{3}$ by the equation: $2 \mathrm{Al}_{2} \mathrm{O}_{3}+3 \mathrm{Hf}=4 \mathrm{Al}+3 \mathrm{HfO}_{2}(\triangle \mathrm{G}=-217.9 \mathrm{KJ} / \mathrm{mol}[36])$. Since the thermodynamic stability of $\mathrm{TiO}_{2}$ is lower than $\mathrm{Al}_{2} \mathrm{O}_{3}\left(\triangle \mathrm{G},-736 \mathrm{KJ} / \mathrm{mol}\right.$ for $\mathrm{TiO}_{2}$, $-1312 \mathrm{KJ} / \mathrm{mol}$ for $\mathrm{Al}_{2} \mathrm{O}_{3}, 1150{ }^{\circ} \mathrm{C}$ ), internal oxidation of $\mathrm{Ti}$ as $\mathrm{TiO}_{2}$ is not possible [37]. 
That means that Ti could continuously diffuse into the TGO.
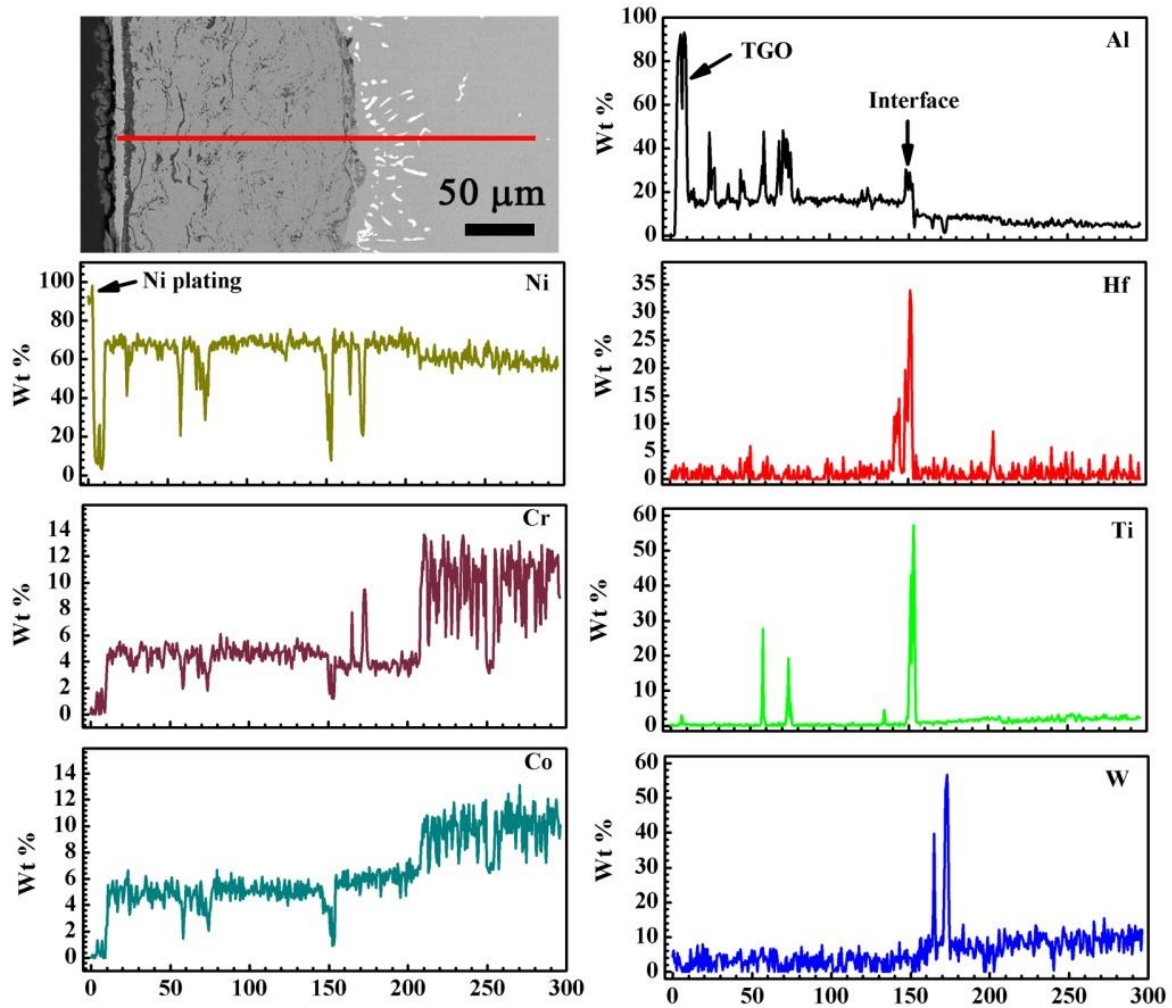

Fig. 11 The EDS line scan on the cross-section of the NiAl+DZ125 sample after $100 \mathrm{~h}$ oxidation.

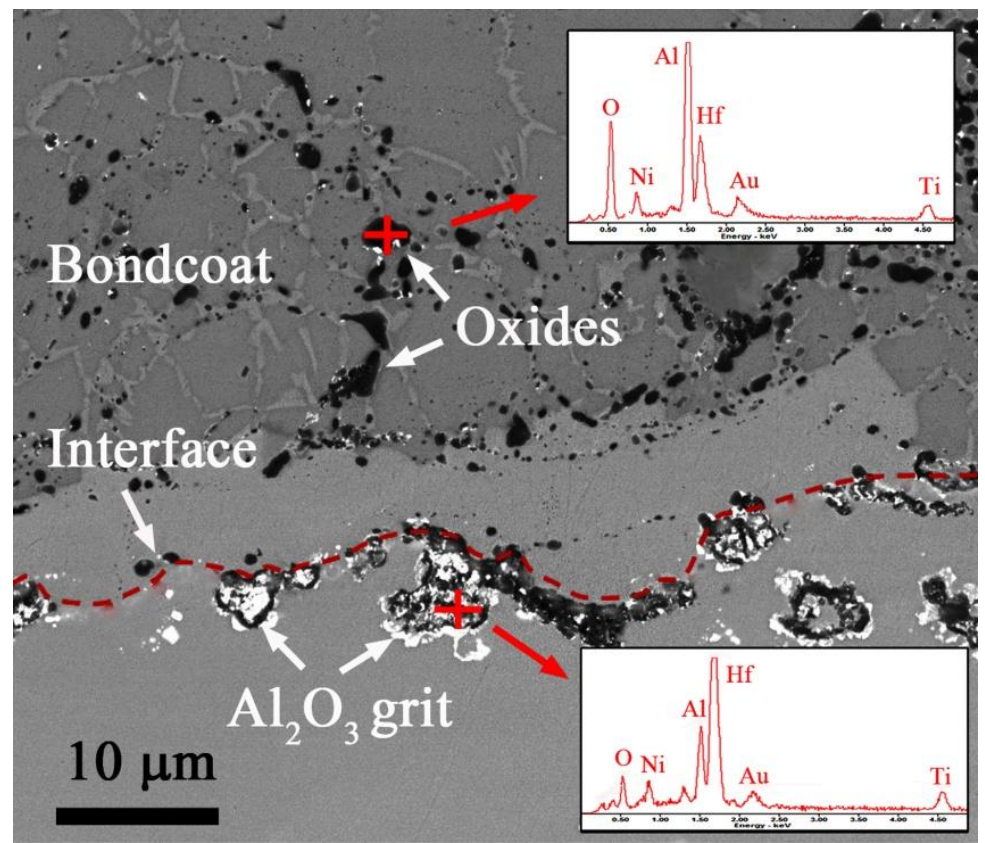

Fig. 12 The cross-sectional micrograph of the NiAl+DZ125 sample after $100 \mathrm{~h}$ oxidation at $1150^{\circ} \mathrm{C}$. The insets present the EDS results of the areas marked by red crosses. 


\section{Discussion}

The results presented here provide a detailed examination of the oxidation behavior of the $\mathrm{NiAl}(\mathrm{Hf})$ bond coat systems, and compared with the NiCoCrAlY samples. It was demonstrated that the oxidation performance of the bond coat systems is not only directly dependent on the bond coat chemistry, but also substantially affected by the chemistry of the superalloy substrate.

\subsection{Factors influencing the TGO growth rate}

In section 3.3, it was found that the oxidation rates of the bond coats were largely different. For the $\mathrm{NiAl}(\mathrm{Hf})$ bond coats, since the spinel oxide only distributed randomly as "islands" at the TGO surface, the oxidation of the bond coats mainly related to the growth of $\mathrm{Al}_{2} \mathrm{O}_{3}$ oxide. The lowest oxidation rates of the two NiAlHf bond coats were attributed to the suppressing effect of Hf on TGO growth. For the NiCoCrAlY bond coats, though containing Y, still exhibited a high growth rate, which was attributed to the fast growth of spinel oxide (Fig. 4). In addition, compared with the bond coats on DZ125L, the oxidation rates of those on DZ125 were relatively lower, especially for the NiAl bond coats. This indicates an influence of the substrate composition on the oxidation rates of the bond coats. However, this effect was sensitive to the chemistry of the bond coats, i.e., the substrate effect was more obvious for the RE-free bond coats $(\mathrm{NiAl})$ than that for the RE-containing ones (NiAlHf, NiCoCrAlY). Compared with the Hf-containing superalloy DZ125, the Hf-free DZ125L has more $\mathrm{Ti}$, while the concentrations of other elements are comparable (Table. 1). So the difference in the substrate effect between DZ125L and DZ125 should be ascribed to the different concentrations of $\mathrm{Hf}$ and Ti.

Contrary to $\mathrm{Hf}$, Ti has been widely reported to has a promoting effect on TGO growth $[5,37,38]$. Though the oxidation rates between the NiAl+DZ125L and $\mathrm{NiAl+DZ125}$ were largely different, no discernible difference was found on the TGO microstructure between them, and no $\mathrm{HfO}_{2}$ oxide was observed in the TGO on the NiAl+DZ125 sample (Fig. 9 and Fig. 10). These findings indicate the absence of large amount of Hf in DZ125 being incorporated to the TGO, at least not enough to modify 
the TGO microstructure and growth mechanism. In addition, both the concentration and diffusion ability of Ti are higher than Hf, so Ti can diffuse more quickly than $\mathrm{Hf}$ into the bond coats and affect the TGO growth. So it reasonably suggests that the difference in the substrate effect on the TGO growth is mainly attributed to the different Ti concentrations between DZ125L and DZ125.

\subsection{Factors influencing the spallation degree}

As shown in Fig. 4, the spallation pattern of the TGO for all the samples were the same. The TGO spallation first occurred at the weak regions (e.g. pores, cracks), where the spinel oxide developed (Fig. 5). The detached area created new edge, and then the TGO delamination propagated though edge delamination. For a TGO layer formed on the bond coat, interfacial cracks would propagate when the stored strain energy release rate $G$ exceeds the interfacial fracture toughness $G_{\text {c }}[39,40]$. The delamination driving force $G$ is a function of the TGO thickness and stress [34]:

$$
G=\frac{1}{2}\left(\frac{1-v^{2}}{E}\right) \sigma_{o}^{2} h
$$

where $h$ is the TGO thickness, $E$ and $v$ are the Young' modulus and Poisson' ratio of the TGO, respectively. $\sigma_{o}$ is the CTE mismatch stress, which is approximately [35]:

$$
\sigma_{o}=\frac{E}{1-v} \Delta \alpha \Delta T
$$

where $\Delta \alpha$ is the difference in the thermal expansion coefficient of the TGO and substrate, and $\Delta T$ is the temperature drop upon cooling. By assuming the elastic strain energy density is constant through thickness, the driving force (strain energy release rate) scales linearly with the TGO thickness $h$, and hence parabolically with the oxidation time, $t$.

In this work, the interfacial fracture toughness $G_{\mathrm{c}}$ refers to the adherence between the TGO and the bond coat $[34,41]$. Previous work indicated that failure of the TGO was though mix mode [42]. The interfacial toughness usually depends on the 
substrate chemistry and impurity segregation. It decreases with an increase of the oxidation time as impurities segregate to the interface and imperfections (e.g., pores) grow [41, 43, 44]. Addition of RE into the bond coat or the substrate could improve the interfacial toughness [5, 34]. As shown in Fig. 9, the TGO on the NiAl+DZ125L sample exhibited a porous microstructure, which decreased the actual contact area between the TGO and the bond coat and hence resulted in a lower interfacial toughness. During high temperature exposure, interfacial pores form due to Kirkendall effect, which can grow rapidly by the presence of intrinsic impurities in metal substrates, especially S and C $[19,35,37]$. It has been widely reported that REs, such as Hf, can substantially inhibit this phenomenon by: (a) modifying the TGO growth mechanism by suppressing $\mathrm{Al}$ outward diffusion, e.g. mitigating the Kirkendall effect; (b) eliminating the harmful $\mathrm{S}$ effect by preventing $\mathrm{S}$ from segregating to the alloy/TGO interface. For NiAlHf bond coats, a large amount of $\mathrm{HfO}_{2}$ oxide existed with the TGO and changed the growth mechanism, resulting in a low growth rate and a columnar microstructure. However, though no $\mathrm{HfO}_{2}$ oxide was observed in the TGO on the NiAl+DZ125 sample (Fig. 9), which still exhibited a dense microstructure (Fig. 11c). Considering these situations, it reasonably suggests that though both mechanism (a) and (b) are at play, the mechanism (b) is mainly responsible for the increase of the interfacial adherence. Previous work also show that Ti could weaken the bond coat/TGO interface to some extent $[5,37]$. However, it is reasonable to suggest that this is not the primary factor for the bond coat/TGO interface degradation, as the TGO formed on the bond coats deposited on DZ125 possesses good adherence while DZ125 also contains Ti. 


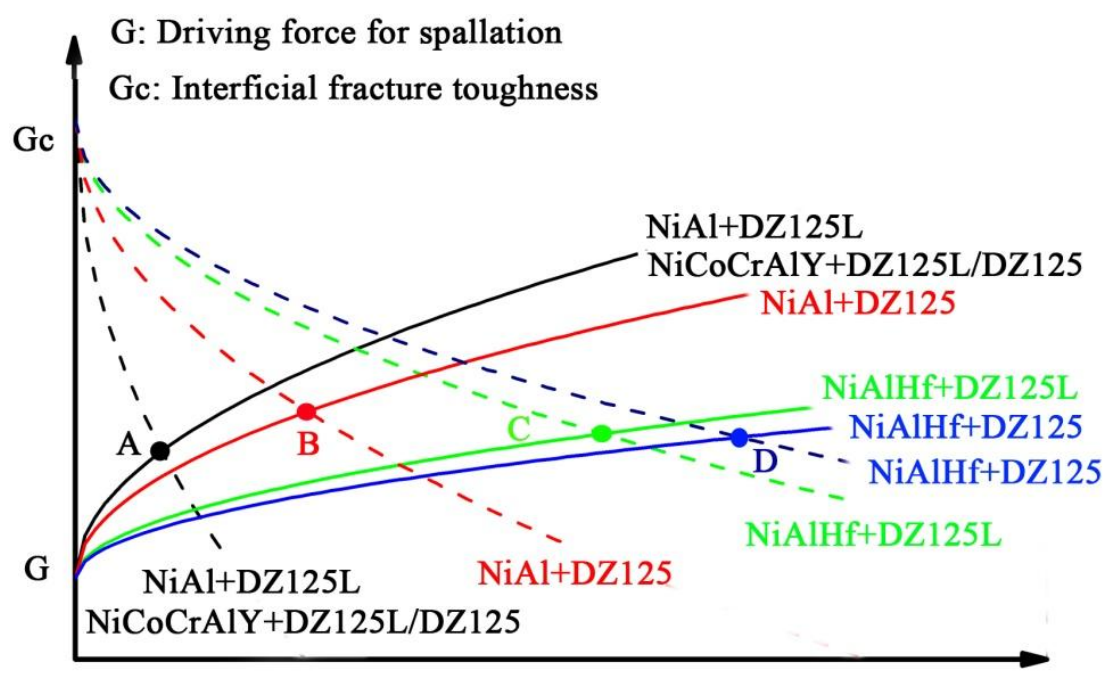

Exposure time, $\mathrm{h}$

Fig. 13 Schematic illustration of the evolution of the spallation driving force $G$ (solid lines) and the interfacial fracture toughness $G_{\mathrm{c}}$ (dashed lines) during oxidation, where the intersections A-D represent the oxidation time that the spallation starts to initiate.

These phenomena indicate that the interfacial toughness of the different bond coat systems were not the same. The interfacial toughness for NiAlHf+DZ125 was highest due to the presence Hf both in the bond coat and the substrate, followed by $\mathrm{NiAlHf}+\mathrm{DZ125L}$ (with no Hf), NiAl+DZ125 (with Hf). This assumption is reasonable since NiAlHf+DZ125L exhibited less TGO spallation than NiAl+DZ125, indicating that adding $\mathrm{Hf}$ into the bond coat is more effective than into the substrate. Then the $\mathrm{NiAl+DZ125L}$ had the lowest interfacial toughness due to no Hf presence in the bond coat and the substrate. For NiCoCrAlY, though containing Y, the elements $\mathrm{Cr}$ and $\mathrm{Co}$ could compromise the beneficial effect. Also, the TGO formed on the NiCoCrAlY bond coat contains a large amount of spinel oxide, which is porous and brittle [32]. As shown in Fig. 7, both NiCoCrAlY+DZ125L and NiCoCrAlY+DZ125 showed worst oxidation resistance, which were comparable with $\mathrm{NiAl}+\mathrm{DZ} 125 \mathrm{~L}$. Thus, for simplicity, the interfacial toughness for NiCoCrAlY+DZ125L and NiCoCrAlY+DZ125 can be roughly ranked as the lowest category (Fig. 13).

The kinetics of the degradation of $G_{\mathrm{c}}$ with exposure time are still open to debate, while a parabolic kinetics might be reasonable, considering the processes of 
solute elements diffusing to the bond coat/TGO interface and the growth of interfacial imperfections. The situation is then envisaged in Fig. 13, which is a schematic illustration of the evolution of the spallation driving force $G$ and the interfacial fracture toughness $G_{\mathrm{c}}$. Initially, to a first-order approximation and for any choice of bond coat, $G_{\mathrm{c}}$ should be approximately equal for all the bond coat systems, considering the identical preparation process [34]. However, with time increasing, it decreases - rapidly for the NiAl and NiCoCrAlY bond coats, but much more slowly for the NiAlHf ones. In addition, for a given bond coat, $G_{\mathrm{c}}$ decreases more rapidly when being coated on DZ125L than on DZ125.

Our findings have implications for the design of TBC systems for high-temperature applications. Firstly, with optimized processes and parameters, the plasma-sprayed NiAlHf bond coat showed significantly improved oxidation performance than the conventional NiCoCrAlY bond coat, suggesting NiAlHf is a promising candidate for thermal barrier coating application. Secondly, it is confirmed that the chemistry of the superalloy substrate affected the oxidation performance of the bond coat system - Hf addition in the superalloy could improve the bond coat oxidation resistance. However, this effect was essentially sensitive to the chemistry of the bond coat employed - obvious for the RE-free NiAl bond coats, but much less obvious for the RE-containing bond coats (NiAlHf, NiCoCrAlY).

\section{Conclusion}

The following conclusions can be drawn from this work:

(1) With optimized processes and parameters, the plasma-sprayed NiAlHf bond coat reveals significantly improved oxidation performance compared with the conventional NiCoCrAlY bond coat.

(2) Hf addition in the bond coat is more effective than in the superalloy for improving the bond coat oxidation performance.

(3) The superalloy substrate composition could influence the oxidation performance of the bond coat system - Hf addition in the superalloy improves the 
bond coat oxidation resistance. However, this effect is essentially sensitive to the chemistry of the bond coat employed - obvious for the RE-free NiAl bond coats, but much less obvious for the RE-containing bond coats (NiAlHf, NiCoCrAlY).

\section{Acknowledgement}

This work was supported by the Baotou-SJTU innovation guidance fund project, the National Natural Science Foundation of China (Grant No. 51402058), and CNPEC financial support (Grant No. 007-EC-B-2014-C83-PS10-00065).

\section{References}

[1] D.B. Miracle, Overview No. 104 The physical and mechanical properties of NiAl, Acta Metall. Mater. 41 (1993) 649-684.

[2] I. Baker, A review of the mechanical properties of B2 compounds, Mater. Sci. Eng. A 192-193 (1995) 1-13.

[3] L. Wei, H. Peng, F. Jia, L. Zheng, S. Gong, H. Guo, Cyclic oxidation behavior of $\mathrm{Hf} / \mathrm{Zr}$ co-doped EB-PVD $\beta$-NiAl coatings at $120{ }^{\circ} \mathrm{C}$, Surf. Coat. Technol. 276 (2015) 721-725.

[4] X. Gong, H. Peng, Y. Ma, H. Guo, S. Gong, Microstructure evolution of an EB-PVD $\mathrm{NiAl}$ coating and its underlying single crystal superalloy substrate, J. Alloys Comp. 672 (2016) 36-44.

[5] Y. Zhou, L. Wang, G. Wang, D. Jin, W. Hao, X. Zhao, J. Zhang, P. Xiao, Influence of substrate composition on the oxidation performance of nickel aluminide coating prepared by pack cementation, Corros. Sci. 110 (2016) 284-295.

[6] Z.D. Xiang, P.K. Datta, Formation of Hf- and W-modified aluminide coatings on nickel-base superalloys by the pack cementation process, Mater. Sci. Eng. A 363 (2003) 185-192.

[7] Y. Zhou, X. Zhao, C. Zhao, W. Hao, X. Wang, P. Xiao, The oxidation performance 
for $\mathrm{Zr}$-doped nickel aluminide coating by composite electrodepositing and pack cementation, Corros. Sci. 123 (2017) 103-115.

[8] Y. Zhang, J.A. Haynes, B.A. Pint, I.G. Wright, W.Y. Lee, Martensitic transformation in CVD NiAl and (Ni,Pt)Al bond coatings, Surf. Coat. Technol. 163 (2003) 19-24.

[9] Y. Zhang, J.A. Haynes, G. Wright, B.A. Pint, K.M. Cooley, W.Y. Lee, P.K. Liaw, Effects of Pt incorporation on the isothermal oxidation behavior of chemical vapor deposition aluminide coatings, Metall. Mater. Trans. A 32 (2001) 1727-1741.

[10] J.A. Hearley, J.A. Little, A.J. Sturgeon, The effect of spray parameters on the properties of high velocity oxy-fuel NiAl intermetallic coatings, Surf. Coat. Technol. 123 (2000) 210-218.

[11] Q. Zhang, C.J. Li, X.R. Wang, Z.L. Ren, C.X. Li, G.J. Yang, Formation of NiAl Intermetallic Compound by Cold Spraying of Ball-Milled Ni/Al Alloy Powder Through Postannealing Treatment, J. Therm. Spray Tech. 17 (2008) 715-720.

[12] P. Niranatlumpong, C.B. Ponton, H.E. Evans, The Failure of Protective Oxides on Plasma-Sprayed NiCrAlY Overlay Coatings, Oxid. Met. 53 (2000) 241-258.

[13] Z. Zou, L. Jia, L. Yang, X. Shan, L. Luo, F. Guo, X. Zhao, P. Xiao, Role of internal oxidation on the failure of air plasma sprayed thermal barrier coatings with a double-layered bond coat, Surf. Coat. Technol. 319 (2017) 370-377.

[14] J. Jiang, Z. Zou, W. Wang, X. Zhao, Y. Liu, Z. Cao, Effect of internal oxidation on the interfacial morphology and residual stress in air plasma sprayed thermal barrier coatings, Surf. Coat. Technol. 334 (2018) 215-226.

[15] R.L. Orban, M. Lucaci, M. Rosso, M.A. Grande, NiAl Behavior at Plasma Spray Deposition, Mater. Sci. Forum 534-536 (2007) 1545-1548.

[16] R.L. Orban, M. Lucaci, M. Rosso, M.A. Grande, NiAl Oxidation and Corrosion Resistant Coatings Obtained by Thermal Spraying, Adv. Mater. Res. 23 (2007) 273-276.

[17] X. Fan, L. Zhu, W. Huang, Investigation of NiAl intermetallic compound as bond coat for thermal barrier coatings on Mg alloy, J. Alloys Comp. 729 (2017) 617-626.

[18] V.K. Tolpygo, K.S. Murphy, D.R. Clarke, Effect of Hf, Y and C in the underlying 
superalloy on the rumpling of diffusion aluminide coatings, Acta Mater. 56 (2008) 489-499.

[19] D. Li, H. Guo, D. Wang, T. Zhang, S. Gong, H. Xu, Cyclic oxidation of $\beta-\mathrm{NiAl}$ with various reactive element dopants at $1200{ }^{\circ} \mathrm{C}$, Corros. Sci. 66 (2013) 125-135.

[20] B.A. Pint, Experimental observations in support of the dynamic-segregation theory to explain the reactive-element effect, Oxid. Met. 45 (1996) 1-37.

[21] B.A. Pint, I.G. Wright, W.Y. Lee, Y. Zhang, K. Prüßner, K.B. Alexander, Substrate and bond coat compositions: factors affecting alumina scale adhesion, Mater. Sci. Eng. A 245 (1998) 201-211.

[22] U. Schulz, M. Menzebach, C. Leyens, Y.Q. Yang, Influence of substrate material on oxidation behavior and cyclic lifetime of EB-PVD TBC systems, Surf. Coat. Technol. 146-147 (2001) 117-123.

[23] R.R. Adharapurapu, J. Zhu, V.S. Dheeradhada, D.M. Lipkin, T.M. Pollock, Effective Hf-Pd Co-doped $\beta$-NiAl(Cr) coatings for single-crystal superalloys, Acta Mater. 76 (2014) 449-462.

[24] F. Yang, E. Liu, Z. Zhi, J. Tong, L. Ning, Influence of Ti content on microstructure, mechanical properties and castability of directionally solidified superalloy DZ125L, Mater. Design 61 (2014) 41-49.

[25] J. Zang, P. Song, J. Feng, X. Xiong, R. Chen, G. Liu, J. Lu, Oxidation behaviour of the nickel-based superalloy DZ125 hot-dipped with Al coatings doped by Si, Corros. Sci. 112 (2016) 170-179.

[26] Z. Zou, C. Xing, L. He, X. Shan, L. Luo, X. Zhao, F. Guo, P. Xiao, A highly strain and damage-tolerant thermal barrier coating fabricated by electro-sprayed zirconia hollow spheres, J. Am. Ceram. Soc. 101 (2018) 4375-4386.

[27] Y. Bai, L. Zhao, Y.M. Qu, Q.Q. Fu, Y. Wang, K. Liu, J.J. Tang, B.Q. Li, Z.H. Han, Particle in-flight behavior and its influence on the microstructure and properties of supersonic-atmospheric-plasma-sprayed nanostructured thermal barrier coatings, J. Alloys Comp. 644 (2015) 873-882.

[28] S. Deshpande, A. Kulkarni, S. Sampath, H. Herman, Application of image analysis for characterization of porosity in thermal spray coatings and correlation with small 
angle neutron scattering, Surf. Coat. Tech. 187 (2004) 6-16.

[29] L. Qiu, F. Yang, W. Zhang, X. Zhao, P. Xiao, Effect of Al content on the lifetime of thermally grown oxide formed on $\mathrm{Ni}-\mathrm{Al}$ alloys after isothermal oxidation, Corros. Sci. 89 (2014) 13-20.

[30] T. Patterson, A. Leon, B. Jayaraj, J. Liu, Y.H. Sohn, Thermal cyclic lifetime and oxidation behavior of air plasma sprayed CoNiCrAlY bond coats for thermal barrier coatings, Surf. Coat. Technol. 203 (2008) 437-441.

[31] A. Ilbagi, P.D. Khatibi, H. Henein, R. Lengsdorf, D.M. Herlach, Effect of cooling rate on solidification of Al-Ni alloys, J. Phys: Confer. Ser. 327 (2011) 012010.

[32] L. Luo, X. Shan, Z. Zou, C. Zhao, X. Wang, A. Zhang, X. Zhao, F. Guo, P. Xiao, A high performance NiCoCrAlY bond coat manufactured using laser powder deposition, Corros. Sci. 126 (2017) 356-365.

[33] J.S. Wang, A.G. Evans, Measurement and analysis of buckling and buckle propagation in compressed oxide layers on superalloy substrates, Acta Mater. 46 (1998) 4993-5005.

[34] R.T. Wu, K. Kawagishi, H. Harada, R.C. Reed, The retention of thermal barrier coating systems on single-crystal superalloys: Effects of substrate composition, Acta Mater. 56 (2008) 3622-3629.

[35] C. Zhao, Y. Zhou, Z. Zou, L. Luo, X. Zhao, F. Guo, P. Xiao, Effect of alloyed Lu, $\mathrm{Hf}$ and $\mathrm{Cr}$ on the oxidation and spallation behavior of NiAl, Corros. Sci. 126 (2017) 334-343.

[36] R.E. Loehman, F.M. Hosking, B. Gauntt, P.G. Kotula, P. Lu, Reactions of Hf-Ag and $\mathrm{Zr}-\mathrm{Ag}$ alloys with $\mathrm{Al}_{2} \mathrm{O}_{3}$ at elevated temperatures, J. Mater. Sci. 40 (2005) 2319-2324.

[37] D. Naumenko, B.A. Pint, W.J. Quadakkers, Current Thoughts on Reactive Element Effects in Alumina-Forming Systems: In Memory of John Stringer, Oxid. Met. 86 (2016) 1-43.

[38] W.J. Quadakkers, D. Naumenko, L. Singheiser, H.J. Penkalla, A.K. Tyagi, A. Czyrska-Filemonowicz, Batch to batch variations in the oxidation behaviour of alumina forming Fe-based alloys, Mater. Corros. 51 (2000) 350-357. 
[39] A.G. Evans, D.R. Mumm, J.W. Hutchinson, G.H. Meier, F.S. Pettit, Mechanisms controlling the durability of thermal barrier coatings, Prog. Mater. Sci. 46 (2001) $505-553$.

[40] T. Xu, M.Y. He, A.G. Evans, A numerical assessment of the durability of thermal barrier systems that fail by ratcheting of the thermally grown oxide, Acta Mater. 51 (2003) 3807-3820.

[41] R.W. Jackson, D.M. Lipkin, T.M. Pollock, Thermal barrier coating adherence to Hf-modified B2 NiAl bond coatings, Acta Mater. 80 (2014) 39-47.

[42] J.S. Wang, A.G. Evans, Effects of strain cycling on buckling, cracking and spalling of a thermally grown alumina on a nickel-based bond coat, Acta Mater. 47 (1999) 699-710.

[43] P.Y. Hou, Segregation Phenomena at Thermally Grown $\mathrm{Al}_{2} \mathrm{O}_{3} /$ Alloy Interfaces, Annu. Rev. Mater. Res. 38 (2008) 275-298.

[44] X. Zhao, J. Liu, D.S. Rickerby, R.J. Jones, P. Xiao, Evolution of interfacial toughness of a thermal barrier system with a Pt-diffused $\gamma / \gamma^{\prime}$ bond coat, Acta Mater. 59 (2011) 6401-6411. 